\title{
1 A chromosome-level genome assembly of a maize elite breeding line Dan340
}

2 Yikun Zhao ${ }^{1,5}$, Yuancong Wang ${ }^{2,5}$, De $\mathrm{Ma}^{3,5}$, Guang Feng ${ }^{4}$, Yongxue Huo ${ }^{1}$, Zhihao

3 Liu ${ }^{1}$, Ling Zhou ${ }^{2}$, Yunlong Zhang ${ }^{1}$, Liwen $\mathrm{Xu}^{1}$, Liang $\mathrm{Wang}^{4}$, Han $\mathrm{Zhao}^{2, *}$, Jiuran

4 Zhao $^{1, *}$, Fengge Wang ${ }^{1, *}$

$5 \quad{ }^{1}$ Maize Research Center, Beijing Academy of Agricultural and Forest Sciences (BAAFS)/Beijing

$6 \quad$ Key Laboratory of Maize DNA Fingerprinting and Molecular Breeding

72 Provincial Key Laboratory of Agrobiology, Institute of Crop Germplasm and Biotechnology,

8 Jiangsu Academy of Agricultural Sciences

$9 \quad{ }^{3}$ Novogene Bioinformatics Institute

${ }^{4}$ Dandong Academy of Agricultural Sciences

$\mathbf{5}$ These authors contributed equally to this article.

*Correspondence: Han Zhao (zhaohan@jaas.ac.cn), Jiuran Zhao (maizezhao@126.com),

\section{Key findings}

1. The final assembly of Dan340 genome was $2,348.72 \mathrm{Mb}$, including 2,738 contigs and 2,315 scaffolds with a N50 of $41.49 \mathrm{Mb}$ and $215.35 \mathrm{Mb}$, respectively.

2. The percent of reads mapped to the reference genome was up to $97.48 \%$.

3. The results showed that $96.84 \%$ of the plant single-copy orthologues were complete. Complete single-copy and multi copy genes accounted for $87.36 \%$ and $9.48 \%$ of the genes, respectively. Taken together, these results indicated that our Dan340 genome assembly presented high quality and coverage. 


\section{Abstract}

The maize cultivar Dan340 is an excellent backbone inbred line of Luda Red Cob

Group with several desirable characters, such as disease resistance, lodging resistance, high combining ability, wide adaptability and so on. In this study, we constructed a high-quality chromosome-level reference genome for Dan340 by combining PacBio long HiFi sequencing, Illumina short reads and chromosomal conformational capture (Hi-C) sequencing reads. The final assembly of Dan340 genome was 2,348.72 Mb, including 2,738 contigs and 2,315 scaffolds with a N50 of 41.49 Mb and 215.35 Mb, respectively. The percent of high quality Illumina reads mapped to the reference genome was up to $97.48 \%$. The assembly of this genome will not only facilitate our understanding about intraspecific genome diversity in maize, but also provides a novel resource for maize breeding.

\section{Background}

Maize (Zea mays ssp. mays L.) is one of the most important crops grown worldwide for food, forage, and biofuel, with an annual production of more than 1 billion tons (Yang et al., 2017). With the rapid growth of human population and economic demand, it has been predicted that maize will account for $45 \%$ of total cereal demand by the year 2050 (Hubert et al., 2010). In addition, it is also an important model organism for fundamental research in genetics and genomics (Hake and Ross-Ibarra, 2015).

Several reference genome of common maize inbred line in breeding have been released since 2009 (Schnable et al., 2009; Hirsch et al., 2016; Jiao et al., 2017; Sun et 
al., 2018; Li et al., 2019). The maize genome exhibits high levels of genetic diversity among different inbred lines (Lu et al., 2015; Yang et al., 2017; Sun et al., 2018).

The maize cultivar Dan340 is an excellent backbone inbred line of Luda Red Cob

Group with several desirable characters, such as disease resistance, lodging resistance, high combining ability, wide adaptability and so on (Zhang et al., 2018).

In the present study, we constructed a high-quality chromosome-level reference genome for Dan340 by combining PacBio long HiFi sequencing, Illumina short reads and chromosomal conformational capture (Hi-C) sequencing reads. The assembly of this genome will not only facilitate our understanding about intraspecific genome diversity in maize, but also provides a novel resource for maize breeding improvement.

\section{Plant material and DNA sequencing}

Inbred line Dan340 was selected for genome sequencing and assembly because it is an elite maize cultivar, which plays an important role in maize breeding and genetic research. The plants were grown at $25^{\circ} \mathrm{C}$ in a greenhouse of Beijing Academy of Agriculture and Forestry Sciences, Beijing, China. Fresh and tender leaves were harvested from the best-growing individual and immediately frozen in liquid nitrogen, followed by preservation at $-80^{\circ} \mathrm{C}$ in the laboratory prior to DNA extraction. Genomic DNA was extracted from the leaf tissue of a single plant using the DNAsecure Plant Kit (Tiangen Biotech Co., Ltd., Beijing, China). To ensure that DNA extracts were useable for all types of genomic libraries, the quality and quantity 
were evaluated using a NanoDrop 2000 spectrophotometer (NanoDrop Technologies, Wilmington, DE, USA) and electrophoresis on a $0.8 \%$ agarose gel, respectively. PacBio circular consensus sequencing (CCS) libraries were prepared using SMRTbell Express Template Prep Kit 2.0 (Pacific Biosciences Ref. No. 101-685-400), following the manufacturer's protocols, and subsequently sequenced on the PacBio sequel II platform (Pacific Biosciences, Menlo Park, CA, USA). Consensus reads (CCS reads, also termed HiFi reads) were generated using ccs software v.3.0.0 (https://github.com/pacificbiosciences/unanimity/) with the parameter '--min-passes 3 --min-rq 0.99 '. The total CCS yield was $63.54 \mathrm{~Gb}$, with a mean read length of 15.60 $\mathrm{kb}$.

In addition, one Illumina paired-end sequencing library with an insert size of $350 \mathrm{bp}$ was generated using NEB Next Ultra DNA Library Prep Kit (NEB, USA) following manufacturer's protocol, and subsequently sequenced using an Illumina HiSeq X Ten platform (Illumina, San Diego, CA, USA) in Novogene Bioinformatics Institute, Beijing, China. Approximately $80.66 \mathrm{~Gb}(\sim 20 \mathrm{X})$ of Illumina sequencing data were obtained.

One Hi-C library was constructed using young leaves following the published procedures with certain modifications (Belton et al., 2012). In brief, approximately 5-g leaf samples were cut into minute pieces and cross-linked by $4 \%$ formaldehyde solution at room temperature in a vacuum for $30 \mathrm{~min}$. Then, the sample was mixed with excess $2.5 \mathrm{M}$ glycine to quench the cross linking reaction for $5 \mathrm{~min}$ and then 
placed on ice for $15 \mathrm{~min}$. The cross-linked DNA was extracted and then digested with

MboI restriction enzyme. The sticky ends of the digested fragments were biotinylated and proximity ligated to form ligation junctions that were enriched for and then ultrasonically sheared to a size of 200-600 bp. The biotin-labelled DNA fragments were pulled down and ligated with Illumina paired-end adapters and then amplified by PCR to produce the Hi-C sequencing library. The library was sequenced using an Illumina HiSeq X Ten platform (Illumina, San Diego, CA, USA).

\section{Genome assembly}

To obtain a high quality genome assembly of Dan340, we employed both PacBio HiFi sequences and Illumina short-read, with scaffolding informed by chromosomal conformation capture (Hi-C). The assembly was performed in a stepwise fashion.

First, de novo assembly of the long CCS reads generated from the PacBio SMRT Sequencing was performed using Hifiasm (Cheng et al., 2021). In brief, we first used all CCS clean reads to do error correction by performing all-vs-all pairwise alignment between them. In this step, haplotype phasing was achieved using heterozygous SNPs and most sequencing errors had been removed. Then, error-corrected reads were used to construct phased assembly graph by determining if one overlap is among the reads coming from different haplotypes. Next, based on the graph topological structures and the phasing relationship among different haplotypes, Hifiasm produced a primary contigs (p-contigs). Then, Pilon (Walker et al., 2014) was used to perform the second round of error correction with short paired-end reads generated from Illumina Hiseq 
112 (https://bitbucket.org/mroachawri/purge haplotigs/overview) was used to remove

113 redundant sequences formed due to heterozygosity.

114 For Hi-C reads, to avoid reads with artificial bias, we removed the following type of reads: (a) Reads with $\geq 10 \%$ unidentified nucleotides $(\mathrm{N})$; (b) Reads with $>10 \mathrm{nt}$ aligned to the adapter, allowing $\leq 10 \%$ mismatches; (c) Reads with $>50 \%$ bases having phred quality $<5$. The filtered $\mathrm{Hi}-\mathrm{C}$ reads were aligned against the contig assemblies with BWA (version 0.7.8). Reads were excluded from subsequent analysis if they did not align within $500 \mathrm{bp}$ of a restriction site or did not uniquely map, and the number of Hi-C read pairs linking each pair of scaffolds is tabulated. ALLHiC v0.8.12 (Zhang et al., 2019) was used in simple diploid mode to scaffold the genome and optimize the ordering and orientation of each clustered group, producing a chromosomal level assembly. Juicebox Assembly Tools v1.9.8

(https://github.com/aidenlab/Juicebox) (Durand et al., 2016) was finally used to visualize and manually correct the large-scale inversions and translocations to obtain the final pseudo-chromosomes. The final assembly of Dan340 genome was 2,348.72 $\mathrm{Mb}$, including 2,738 contigs and 2,315 scaffolds with a N50 of 41.49 Mb and 215.35 pseudo-chromosomes.

\section{Evaluation of assembly quality}

131 We assessed the quality of the assembly by two independent methods. First, the short reads obtained from the Illumina sequencing data were aligned to the final assembly 
result showed that the percent of reads mapped to the reference genome was up to results showed that $96.84 \%$ of the plant single-copy orthologues were complete.

\section{Conclusions}

1. We assembled the chromosome-level genome of maize elite inbred line Dan340 and 2,315 scaffolds with a N50 of $41.49 \mathrm{Mb}$ and $215.35 \mathrm{Mb}$, respectively.

\section{References}

150 comprehensive technique to capture the conformation of genomes. Methods. 2012; 58,

$151 \quad 268-276$.

152 Cheng H, Concepcion GT, Feng X, Zhang H, Li H. (2021) Haplotype-resolved de

153 novo assembly using phased assembly graphs with hifiasm. Nat Methods. 18, 
Durand NC, Robinson JT, Shamim MS, Machol I, Mesirov JP, Lander ES, Aiden EL.

(2016) Juicebox Provides a Visualization System for Hi-C Contact Maps with

Unlimited Zoom. Cell Syst. 3, 99-101.

Hake S, Ross-Ibarra J. (2015) Genetic, evolutionary and plant breeding insights from the domestication of maize. Elife. 4, e05861.

Hubert B, Rosegrant M, Boekel MA, Ortiz R. (2010). The future of food: scenarios for 2050. Crop Sci. 50, 33-50.

Hirsch CN, Hirsch CD, Brohammer AB, Bowman MJ, Soifer I, Barad O, Shem-Tov D, Baruch K, Lu F, Hernandez AG, Fields CJ, Wright CL, Koehler K, Springer NM, Buckler E, Buell CR, de Leon N, Kaeppler SM, Childs KL, Mikel MA. (2016) Draft Assembly of Elite Inbred Line PH207 Provides Insights into Genomic and Transcriptome Diversity in Maize. Plant Cell. 28, 2700-2714.

Jiao Y, Peluso P, Shi J, Liang T, Stitzer MC, Wang B, Campbell MS, Stein JC, Wei X, Chin CS, Guill K, Regulski M, Kumari S, Olson A, Gent J, Schneider KL,

Wolfgruber TK, May MR, Springer NM, Antoniou E, McCombie WR, Presting GG,

McMullen M, Ross-Ibarra J, Dawe RK, Hastie A, Rank DR, Ware D. (2017)

Improved maize reference genome with single-molecule technologies. Nature. 546, 524-527.

Li C, Song W, Luo Y, Gao S, Zhang R, Shi Z, Wang X, Wang R, Wang F, Wang J, Zhao Y, Su A, Wang S, Li X, Luo M, Wang S, Zhang Y, Ge J, Tan X, Yuan Y, Bi X, He H, Yan J, Wang Y, Hu S, Zhao J. (2019) The HuangZaoSi Maize Genome 
Provides Insights into Genomic Variation and Improvement History of Maize. Mol

Plant. 12, 402-409.

Li H, Durbin R. (2010) Fast and accurate long-read alignment with Burrows-Wheeler transform. Bioinformatics. 26, 589-595.

Lu F, Romay MC, Glaubitz JC, Bradbury PJ, Elshire RJ, Wang T, Li Y, Li Y, Semagn K, Zhang X, Hernandez AG, Mikel MA, Soifer I, Barad O, Buckler ES.

(2015) High-resolution genetic mapping of maize pan-genome sequence anchors. Nat Commun. 6, 6914.

Schnable PS, Ware D, Fulton RS, Stein JC, Wei F, Pasternak S, Liang C, Zhang J, Fulton L, Graves TA, Minx P, Reily AD, Courtney L, Kruchowski SS, Tomlinson C, Strong C, Delehaunty K, Fronick C, Courtney B, Rock SM, Belter E, Du F, Kim K, Abbott RM, Cotton M, Levy A, Marchetto P, Ochoa K, Jackson SM, Gillam B, Chen W, Yan L, Higginbotham J, Cardenas M, Waligorski J, Applebaum E, Phelps L, Falcone J, Kanchi K, Thane T, Scimone A, Thane N, Henke J, Wang T, Ruppert J, Shah N, Rotter K, Hodges J, Ingenthron E, Cordes M, Kohlberg S, Sgro J, Delgado B, Mead K, Chinwalla A, Leonard S, Crouse K, Collura K, Kudrna D, Currie J, He R, Angelova A, Rajasekar S, Mueller T, Lomeli R, Scara G, Ko A, Delaney K, Wissotski M, Lopez G, Campos D, Braidotti M, Ashley E, Golser W, Kim H, Lee S, Lin J, Dujmic Z, Kim W, Talag J, Zuccolo A, Fan C, Sebastian A, Kramer M, Spiegel L, Nascimento L, Zutavern T, Miller B, Ambroise C, Muller S, Spooner W, Narechania A, Ren L, Wei S, Kumari S, Faga B, Levy MJ, McMahan L, Van Buren P, Vaughn 
MW, Ying K, Yeh CT, Emrich SJ, Jia Y, Kalyanaraman A, Hsia AP, Barbazuk WB,

Baucom RS, Brutnell TP, Carpita NC, Chaparro C, Chia JM, Deragon JM, Estill JC, Fu Y, Jeddeloh JA, Han Y, Lee H, Li P, Lisch DR, Liu S, Liu Z, Nagel DH, McCann MC, SanMiguel P, Myers AM, Nettleton D, Nguyen J, Penning BW, Ponnala L, Schneider KL, Schwartz DC, Sharma A, Soderlund C, Springer NM, Sun Q, Wang H, Waterman M, Westerman R, Wolfgruber TK, Yang L, Yu Y, Zhang L, Zhou S, Zhu Q, Bennetzen JL, Dawe RK, Jiang J, Jiang N, Presting GG, Wessler SR, Aluru S, Martienssen RA, Clifton SW, McCombie WR, Wing RA, Wilson RK. (2009) The B73 maize genome: complexity, diversity, and dynamics. Science. 326, 1112-1115. Simão FA, Waterhouse RM, Ioannidis P, Kriventseva EV, Zdobnov EM. (2015) BUSCO: assessing genome assembly and annotation completeness with single-copy orthologs. Bioinformatics. 31, 3210-3212.

Sun S, Zhou Y, Chen J, Shi J, Zhao H, Zhao H, Song W, Zhang M, Cui Y, Dong X, Liu H, Ma X, Jiao Y, Wang B, Wei X, Stein JC, Glaubitz JC, Lu F, Yu G, Liang C, Fengler K, Li B, Rafalski A, Schnable PS, Ware DH, Buckler ES, Lai J. (2018) Extensive intraspecific gene order and gene structural variations between Mo17 and other maize genomes. Nat Genet. 50, 1289-1295.

AUGUSTUS: ab initio prediction of alternative transcripts. Nucleic Acids Res. 34, W435-9.

Walker BJ, Abeel T, Shea T, Priest M, Abouelliel A, Sakthikumar S, Cuomo CA, Zeng Q, Wortman J, Young SK, Earl AM. (2014) Pilon: an integrated tool for 
218 comprehensive microbial variant detection and genome assembly improvement. PLoS

219 One. 9(11):e112963.

220 Yang N, Xu XW, Wang RR, Peng WL, Cai L, Song JM, Li W, Luo X, Niu L, Wang

221 Y, Jin M, Chen L, Luo J, Deng M, Wang L, Pan Q, Liu F, Jackson D, Yang X, Chen

222 LL, Yan J. (2017) Contributions of Zea mays subspecies mexicana haplotypes to

223 modern maize. Nat Commun. 8, 1874.

224 Zhang R, Xu G, Li J, Yan J, Li H, Yang X. (2018) Patterns of genomic variation in

225 Chinese maize inbred lines and implications for genetic improvement. Theor Appl

226 Genet. 131, 1207-1221.

227 Zhang X, Zhang S, Zhao Q, Ming R, Tang H. (2019) Assembly of allele-aware,

228 chromosomal-scale autopolyploid genomes based on Hi-C data. Nature Plants. 5,

$229 \quad 833-845$.

230

231

Table 1 Results of genome assembly assisted by Hi-C technology.

\begin{tabular}{|c|c|c|c|c|}
\hline & $\begin{array}{c}\text { Contig } \\
\text { length (bp) }\end{array}$ & $\begin{array}{c}\text { Scaffold } \\
\text { length (bp) }\end{array}$ & $\begin{array}{l}\text { Contig } \\
\text { number }\end{array}$ & $\begin{array}{c}\text { Scaffold } \\
\text { number }\end{array}$ \\
\hline Total & $2,348,678,871$ & $2,348,721,171$ & 2,738 & 2,315 \\
\hline $\operatorname{Max}$ & $97,718,682$ & $343,826,844$ & - & - \\
\hline $\begin{array}{l}\text { Number } \\
>=2000\end{array}$ & - & - & 2,738 & 2,315 \\
\hline N50 & $41,489,332$ & $215,353,106$ & 20 & 5 \\
\hline N60 & $32,900,726$ & $193,940,028$ & 26 & 6 \\
\hline N70 & $22,291,114$ & $184,974,134$ & 35 & 7 \\
\hline N80 & $11,599,268$ & $165,218,414$ & 49 & 9 \\
\hline N90 & $3,788,017$ & $153,467,472$ & 80 & 10 \\
\hline
\end{tabular}

232 
bioRxiv preprint doi: https://doi.org/10.1101/2021.04.26.441299; this version posted April 28, 2021. The copyright holder for this preprint (which was not certified by peer review) is the author/funder, who has granted bioRxiv a license to display the preprint in perpetuity. It is made available under aCC-BY-NC-ND 4.0 International license.

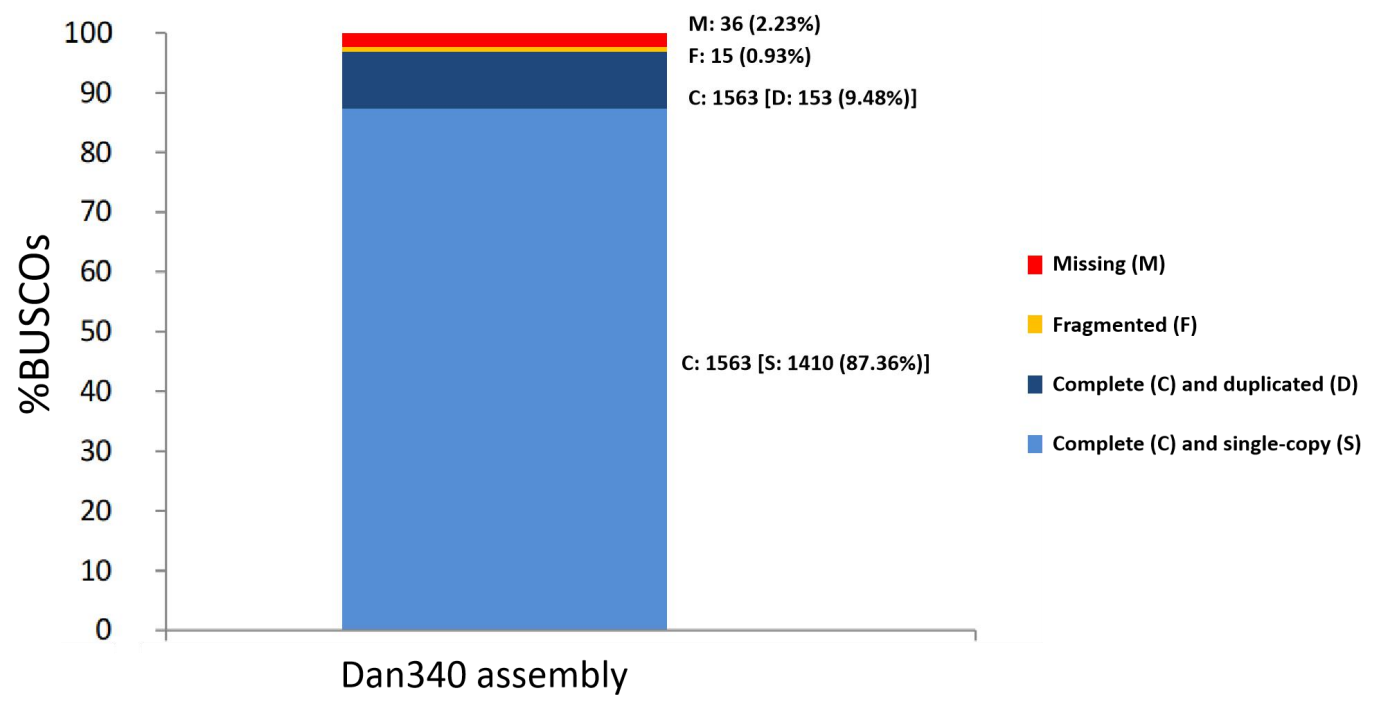

235 Figure 1 BUSCO Assessment Results (Database: embryophyta_odb10, n: 1614) 